\title{
Shock propagation behaviour and determination of Gruneisen state of equation for pultruded polyester/glass fibre-reinforced composites.
}

\author{
MUKHERJI, A. and NJUGUNA, J.
}




\title{
Shock Propagation Behaviour and Determination of Greisen State of Equation for Pultruded Polyester/Glass Fibre-Reinforced Composites
}

\section{Arindam Mukherji ${ }^{1}$ and James Njuguna ${ }^{2}$}

${ }^{1}$ SP Advance Engineering Materials Pvt Ltd, SP Centre, 41/44, Minoo Desai Marg, Colaba, Mumbai. 400 005, India, Email: arindam.mukherji@shapoorji.com

${ }^{2}$ Centre of Advanced Engineering Materials, School of Engineering, Robert Gordon University, Sir Ian Wood Building, Garthdee Road, Aberdeen, AB10 7GJ United Kingdom

Author to whom correspondence should be addressed; Email: j.njuguna@ @rgu.ac.uk Tel.: +44 (0) 1224262304

\begin{abstract}
Polyester fibres reinforced with glass fibres hybridised polyester resin composite (PFR/GFHC) is a unconventional complex high-molecular weight crosslinked network polymer composite, which can be used in the manufacture of structural body parts for lightweight vehicles, armour vest for body protection as well as armours for vehicles. For body armour applications, it is important to determine the dynamic behaviour of PFR/GFHC during high velocity impact. In this work, we propose a method of calculating Gurneisen parameter from the measured Hugoniot in shock velocity - particle velocity of polyester based composites product by high velocity actuated nail gun impact. Several impacts were conducted on pultruded plates using different cartridge with varying nail size. The experimentally measured Hugoniot in shock velocity - particle velocity space was determined as $U s=2.872+1.22 \mathrm{Up}(\rho 0=1.25 \mathrm{~g} / \mathrm{cc})$ and low gradient observed for Gruneisen parameter as calculated from measured Hugoniot against $\mathrm{V}_{0} / \mathrm{V}$ shows higher shock absorption of PFR/GFHC for impact velocity.
\end{abstract}

Keywords: Composites, Gruneisen parameter, Hugoniot, Shock wave, High Velocity Impact

\section{Introduction}

The polyester glass composite is a typical complex high-molecular weight three-dimensional network polymer. It is well-known for excellent properties, such as being good Impact, having thermal stability, good chemical resistance, low electrical conductivity, large radiation 
resistance, high tensile strength [1]. Due to the excellent properties, polyester /glass fibre reinforced composites are widely used in many engineering and commodity application. However, glass fibre based thermoset composite are heavy which limits its extensive use as body armour. Dry fabrics made up by high strength polyester fibres are best lightweight solutions against ballistic impact when hybridised with chopped glass fibres [2,3].

In general, most fibres are classified into woven and nonwoven fabrics depending on the architecture of the fibres. Woven fibres are bundled in weave yarns following are regular pattern, while fibres formed is ordered network consolidated by means of thermal, chemical or mechanical bonds in nonwoven fabrics [1]. These fabrics are of then used in ballistic protection against metallic projectiles [2,3,4,5]. It is well known that these fibres are not efficient protection against small fragments of size similar to that of the yarn to yarn spacing of the woven fabric because the energy is not transferred to the fabric and the projectiles lips through the yarns $[6,7,8]$.

In comparison, non-woven fabrics present lower stiffness and strength but higher deformability than their woven counterparts $[9,10]$. They are very efficient against the impact of small fragments $[6,11,12,13]$ providing equivalent ballistic protection as woven fabrics with one third of the areal weight [14]. The combination of both woven and non-woven fabrics in hybrid laminates is an innovative solution to arrest fragments within a wide range of calibres [15]. The rationale behind this design is very simple: woven fabrics arrest the large and medium size fragments [16,17], while non-wovens trap the smallest fragments $[11,18,19]$. Non-woven materials are stacked facing the projectile to enhance the load transmission into the woven fabric and to reduced damage in woven fabrics at the rear of the armour protecting they yarns from sharp projectiles which may cause localized fibre failure [20,21]. In addition, there are reports of changes in the mechanical response of the nonwoven fabric due to the interaction with the woven layers at the rear of the laminate [22], although the physical mechanisms of the interactions between both types of layers are not well established.

Unlike other materials, thermoplastic polymers and ceramics, there is a paucity of data dealing with the shock response of thermoset resins. This is perhaps surprising as these resins are integral to the construction of considerable civilian and military hardware and structures that is subjected to shock. In the literature, Munson and May [22] investigated three different epoxy resin systems that used different hardening agents. They found that, within experimental error, the measured Hugoniot of the material was the same for each resin. Barnes et al [23] also studied epoxy resins and they measured the Hugoniot value very similar to that of Munson and May. These works assumed a linear shock velocity particle velocity relationship. Barnes et al 
[24] suggested that their resin demonstrated a positive dependence of shear strength with shock stress. This positive dependence has been investigated by Bourne et al [25] and in an accompanying work by Millett et al [26] who used the embedded lateral gauge technique to directly measure the variation of lateral stress. They observed that with increasing shock stress, the lateral stresses decreased resulting in an increase in strength behind the shock. A linear Hugoniot in shock velocity-particle velocity space occurs for a wide range of materials [29] including the aerospace industry standard resin transfer moulding resin (RTM6) used in the manufacture of these epoxy/carbon fibre-reinforced composite (CFRC) laminates [30,31] and glass fibre-reinforced composites (GFRC) [32].

The shock behaviour of GFRC laminates and the shock behaviour of different thicknesses of GFRC in the through-thickness direction was studied by Tsai et al [27]. A multibeam VALYNTM VISAR (Velocity Interferometer System for Any Reflector) laser interferometer was used to measure the particle velocity at the rear surface of the targets. They noticed a distinct knee in the velocity time profile during the rise time of the particle velocity profiles in each of the four experiments. Furthermore, the slope of the velocity time profiles decreased with the thickness of the GFRC target i.e. with the distance of wave propagation. The stress level at which the slope change occurred decreased with increasing GFRC thickness. It was noted that this phenomenon was similar to the elastic-precursor decay observed in elastic viscoplastic materials and for the case of the GFRC tested, the researchers attributed it to a result of both material and geometric dispersion of the shock wave.

It is to be noted that published works have given attention to examining the shock in the through-thickness direction where the direction of all the fibres is perpendicular to the loading axis. For instance, Dandekar et al. [28] have conducted plate impact experiments on an S2based GFRC material in the through-thickness direction and shown that the compression curve, as measured in pressure - particle velocity space, of the GRFC lay in-between that of the material's constituent parts. Their results also indicated that there was a linear relationship between shock velocity $(U s)$ and particle velocity $(U p)$ of the form

$$
U s=C_{0}+S U p
$$

where $C_{0}$ and $S$ are the shock parameters.

On the other hand, the response of a material (Hugoniot) to a resident advancing shock wave is described by the Rankine-Hugoniot relations, which define the conservation of mass, linear momentum and energy across the shock front. 
Precision of pressure values for reflected state curves has less accurate than that for principal Hugoniot state since the compression state accessed techniques are limited. Hence off Hugoniot state, the most common assumption on type of equation of state (EOS) is the Gruneisen assumption - an EOS is a thermodynamic equation describing the state of matter under a given set of physical conditions. Thermodynamic Gruneisen parameter is one of the material parameters which is non-dimensional and is considered to represent the typical characteristics of the material properties. This Gruneisn law leads the so called Gruneisen EOS widely used in high pressure condition. The shock's Hugoniot curve obtained by shock compression experiments is normally used in experiments to give one of the most reliable information on the EOS for solids at very high pressure as the values of shock pressure is estimated in the very high pression. Considering Guneisen is one of the thermodynamic state variables, it is a function of volume as first approximation. Many experimental efforts have been made in the literature including shock compression for porous and continuous materials to estimate the high-pressure behaviour of Grunesin parameter. Hence a direct measurement of Grunesin parameter can well describe the material linear behaviour with high pressure due to high shock loads.

In this study, we have investigated the shock behaviour of a commercially important polyester fibres reinforced with glass fibres hybridised polyester resin composite (PFR/GFHC) at different impact velocity using power actuated nail gun. For the high velocity gas gun, impact pressure generated was minimal due to low velocity resulting into negligible changes in slop gradient when Guneisen parameter is plotted against specific volume change. Hence, experiment were made to investigate the behaviour of material with measurement of Hugonoit and then the calculation of the Grunesin parameter for specific volume change during impact at different impact velocities through power actuated nail gun.

\section{Theoretical Modelling}

In the literature, the Hugoniot modelling is presented in parts in various publications. For completeness to readers benefit, relation between Gruneisen parameters and specific volume change through Hugoniot Parameters is developed. . As depicted in Table I, parameters which are taken theoretically and experimentally, and some Un-known are hereby determined in the follow ups.

Table I 
Calculation for particle velocity of target: Let us consider that the hydrodynamic pressure $P_{H}=P_{2}-P_{1}$ is then,

$P_{2}-P_{1}=\left[\rho_{1}\left(U_{s}\right) U p\right]$

As we know impactor velocity $(U d)$ is the measure of particle velocity and the shock velocity of impactor, then

$U^{i} p=U d-U^{t} p$

$P_{H}=\rho U_{s} U p$

$P_{i}=\rho_{i} U^{i} s U^{i} p$

$P_{t}=\rho_{t} U^{t} s U^{t} p$

During the impact both the hydrodynamic pressure on window and impactor is predicted to be same as per impedance matching

$P i=P_{t}$

and

$P_{H}=\left[\rho\left(S U_{p}+C_{0}\right) U p\right]$

Where $t$ stands for target and $i$ stands for impactor

$\rho_{t} U t s U^{t} p=\rho_{i} U^{i} s U^{i} p$

$\rho_{t} U^{t} S U^{t} p=\rho_{i}\left(S_{i} U^{i} p_{i}+C_{0 i}\right) U^{i} p$

$\rho_{t} U^{t} S U^{t} p=\rho_{i} S_{i} U^{i} p^{2}+\rho_{i} C_{0 i} U^{i} p$

Putting value of equ. (3)

$\rho_{t} U^{t} S U^{t} p=\rho_{i} S_{i} V^{2}+\rho_{i} S_{i} U^{t} p^{2}-2 \rho_{i} S_{i} U^{t} p V+\rho_{i} C_{0 i} V-\rho_{i} C_{0 i} U^{t} p$

$O=\rho_{i} S_{i} V^{2}+\rho_{i} S_{i} U^{t} p^{2}-2 \rho_{i} S_{i} U^{t} p V+\rho_{i} C_{0 i} V-\rho_{i} C_{0 i} U^{t} p-\rho_{t} U s t U^{t} p$

$O=\rho_{i} S_{i} V^{2}+\rho_{i} S_{i} U^{t} p^{2}-2 \rho_{i} S_{i} U^{t} p V+\rho_{i} C_{0 i} V-\rho_{i} C_{0 i} U^{t} p-\rho_{t} U^{t} S U^{t} p$

$\rho_{i} S_{i} U^{t} p^{2}+\left(S_{i} V+C_{0 i}\right) V \rho_{i}-\left(\rho_{i} C_{0 i}+\rho_{t} U^{t} s+2 V \rho_{i} S_{i}\right) U^{t} p=0$

Now, suppose $a=\rho_{i} S_{i}, b=-\left(\rho_{i} C_{0 i}+\rho_{t} U^{t} s+2 V \rho_{i} S_{i}\right)$ and $h=\left(S_{i} V+C_{0 i}\right) V \rho_{i}$

Then we can deduce that

$U^{t} p=\left[-b-\sqrt{ }\left(b^{2}-4 a h\right)\right] / 2 a$

where $\rho_{t}$ is the initial density of the target, $\rho_{i}$ is the initial density of the flyer, $C_{0 i}$ and $S_{i}$ are the Hugoniot parameters of the flyer. The parameters for flyers are provided in Table II in the given case and the initial density of the polyester composite $\left(\rho_{t}\right)$ sample is $1.35 \mathrm{~g} / \mathrm{cm}^{3}$. 
Table II

Relations Between Functional Parameters: Firstly, the relation of shock velocity, particle velocity and density before and after shock from conservation of mass $M_{i}=\rho_{i} \times A \times L_{i}$ and $M_{i}=$ $\rho_{i} x A x\left(t \times v_{i}\right) v_{i}$ is the relative velocity, which equals to $v_{i}=(U s-U i)$ where $\mathrm{U}_{\mathrm{i}}$ is the particle velocity and at initial condition, $U_{P}$ is zero before shock since the mass remain the same before and after shock event. Hence, $M_{i}=\rho_{1} x A x\left(t \times v_{1}\right)=\rho_{2} x A x\left(t \times v_{2}\right)$ can be resolved as follows

$\rho_{1} x A x\left[t x\left(U s-U_{1}\right)\right]=\rho_{2} x A x\left[t x\left(U s-U_{2}\right)\right]$

$\rho_{1} x A x[t \times(U s-0)]=\rho_{2} x A x\left[t x\left(U s-U_{p}\right)\right]$

$\rho_{1} x(U s-0)=\rho_{2} x\left(U s-U_{p}\right)$

This yield the following equation,

$\rho_{1} U s=\rho_{2}\left(U s-U_{p}\right)$

where, $M_{i}=$ mass of the target; $\rho_{1}=$ density before shock, $\rho_{2}=$ density after shock, $L_{i}=$ distance travelled by the particle after shock and $t=$ time taken by the particle to travel distance $L_{i}$.

Relationship of shock velocity, particle velocity, density and pressure before and after shock from conservation of momentum: The next step is on deriving the relationship of shock velocity, particle velocity, density and pressure before and after shock from conservation of momentum. Given that momentum equals to the product of mass and velocity, thus, mass $\mathrm{x}$ velocity and change in momentum per unit time is used for the measurement of force. Therefore, since Force $=P x A=\left(P_{2}-P_{1}\right) \times A$ and $M_{i}=\rho_{1} \times A \times\left(t \times v_{1}\right)$, then, $M_{1}=\rho_{1} x A x(t x$ $\left.v_{1}\right)$ and $M_{2}=\rho_{2} x A x\left(t \times v_{2}\right)$. The momentum equals to

product of mass and velocity of particle, $M_{i} x U_{i}$, and change in momentum per unit time is expressed as,

$\left(M \times U_{2}\right) / t-\left(M \times U_{1}\right) / t=$ Force

$\left[\rho_{2} \times A \times\left(t \times v_{2}\right) U_{2}-\rho_{1} \times A \times\left(t \times v_{1}\right) U_{1}\right] / t=\left(P_{2}-P_{1}\right) \times A$

$\left[\rho_{2}\left(v_{2}\right) U_{2^{-}} \rho_{1}\left(v_{1}\right) U_{1}\right]=\left(P_{2}-P_{1}\right)$

$\left[\rho_{2}\left(U s-U_{2}\right) U_{2-} \rho_{1}\left(U s-U_{1}\right) U_{1}\right]=\left(P_{2}-P_{1}\right)$

$\left[\rho_{2}(U s-U p 2) U_{2^{-}} \rho_{1}\left(U s-U p_{1}\right) U p_{1}\right]=\left(P_{2-} P_{1}\right)$

Since $U_{l}=O=U_{p}$ then,

$\left[\rho_{1}\left(U_{s}\right) U p-\rho_{1}\left(U s-U p_{1}\right) \times 0\right]=\left(P_{2}-P_{1}\right)$ and 
$\left[\rho_{1}\left(U_{s}\right) U p\right]=\left(P_{2}-P_{1}\right)$

Evaluating the relationship of energy, pressure and density before and after from conservation of energy: To determine this relationship, we will need to consider the total energy of the body measures, a summation of total kinetic energy $\left(K . E=1 / 2 m v_{i}^{2}=1 / 2 M i\left(U_{s-} U_{i}\right)^{2}\right)$, total internal energy ( $\varepsilon i M i)$ and the total work done due to constant pressure (i.e. PixA $x$ Li $=$ PixA $x\left(t x U_{s}\right.$ $\left.\left.{ }_{-} U_{i}\right)\right)$. Since, $M_{i}=\rho_{i} x A x\left(t \times v_{i}\right)=\rho_{i} x A x\left(t x U_{s-} U_{i}\right)$ then, $A x\left(t \times U_{s-} U_{i}\right)=\left(M_{i}\right) / \rho_{1}$

The total Energy of the Body would be $E_{1}=E_{2}$ that will lead us into

$1 / 2 M i\left(U_{s-} U_{1}\right)^{2}+\varepsilon_{1} M i+P_{1} x\left(M_{i}\right) / \rho_{1}=1 / 2 M i\left(U_{s-} U_{2}\right)^{2}+\varepsilon_{2} M i+P_{2}\left(M_{i}\right) / \rho_{1}$
$1 / 2\left(U_{s-} U_{1}\right)^{2}+\varepsilon_{1}+P_{1} / \rho_{1}=1 / 2\left(U_{s-} U_{2}\right)^{2}+\varepsilon_{2}+P_{2} / \rho 2$
$\left[1 / 2\left(U_{s-} U_{1}\right)^{2}++P_{1} / \rho_{1}\right]-1 / 2\left(U_{s-} U_{2}\right)^{2}-\left(P_{2} / \rho_{1}\right)=\varepsilon_{2}-\varepsilon_{1}$

Since $U_{l}=0=U_{p}$ where

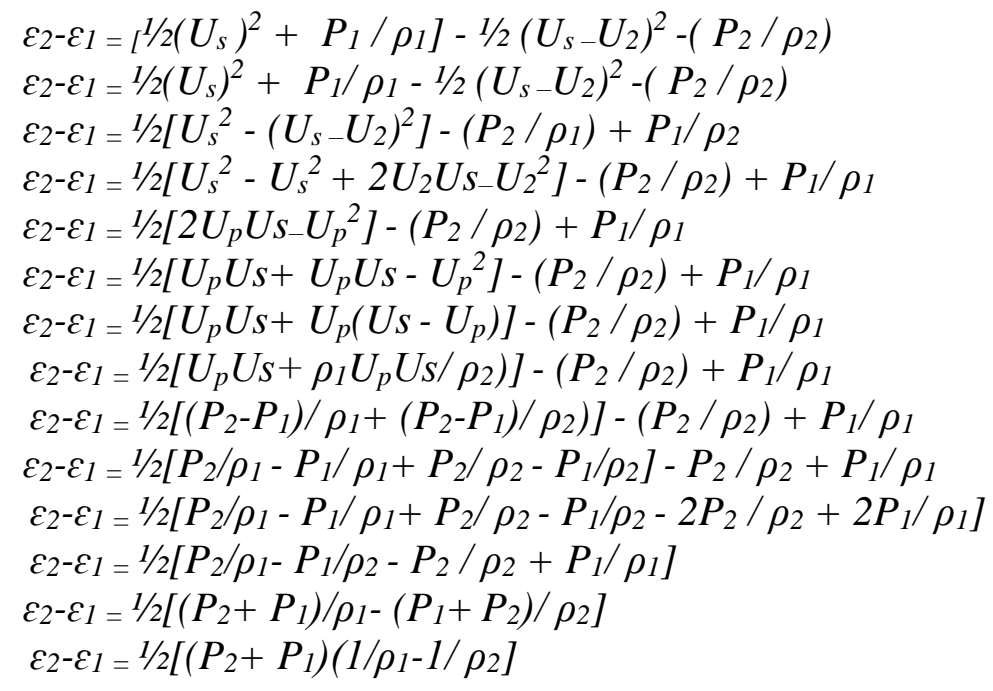

Then we can deduce that

$\varepsilon_{2}-\varepsilon_{1}=1 / 2\left(P_{2}+P_{1}\right)\left(V_{1}-V_{2}\right)$

Determination of the Gruneisen Parameter from Hugoniot equation state equation: As we know specific volume is inverse of density i.e. $V_{i}=1 / \rho_{i}, V_{0}=1 / \rho_{0}$ at initial condition and $V=1 / \rho$ at final condition, then we have $\left[\rho_{1}\left(U_{s}\right) U p\right]=\left(P_{2}-P_{1}\right)$ becomes

$\left[\left(U_{s}\right) U p\right] / V_{0}=\left(P_{2}-P_{1}\right)=P_{H}$

And $\rho_{1} U s=\rho_{2}\left(U s-U_{p}\right)$ yields

$U s / V_{0}=\left(U s-U_{p}\right) / V$ 
Then $1 / V_{0}=1 / V-U_{p} / U s V$ and $U_{p} / U s=\left(1 / V-1 / V_{0}\right) V$ deriving Equation (15) as

$\varepsilon=1 / 2\left(P_{H}\right)(V O-V)$

From Hugonoit equation we know that $U s=C_{0}+S U p$ when this equation is multiplied with inverse of shock velocity, it can be shown that

$C_{0}+S U p=\left(1 / V-1 / V_{0}\right) V / U p=1-V_{0} / V$

$l=C_{0} / U s+S U p / U s$

Hence,

$C_{0} / U s=1-S U p / U s$

$C_{0} / U s=1-S\left(1 / V-1 / V_{0}\right) V$

$C_{0} / U s=1-S+S V / V_{0}$

When we differentiate with $d v$, the Equation (16d), it becomes $\left(1 / U s^{2}\right) C_{0} d U s / d V=S / V_{0}$ and hence $d U s / d V=-S U s^{2} / C_{0} V_{0}$. Again, from Hugonoit linear equation $U s=C_{0}+S U p$ and $U_{s} U p / V_{0}$ $=P_{H}$ and therefore $U p=P_{H} V_{0} / U s$ which can be replaced in general Hugonoit equation and we have $U s=C_{0}+S P_{H} V_{0} / U s$ and thus,

$P_{H}=\left(U s-C_{0}\right) U s / S V_{0}$

Now $P_{H}{ }^{\prime}=d P_{H} / d v$

$$
\begin{aligned}
d P_{H} / d v & =d / d v \times\left(U s^{2} / S V_{0^{-}} C_{0} U s / S V_{0}\right) \\
d P_{H} / d v & =2 U s / S V_{0} x d U s / d v-C_{0} / S V_{0} x d U s / d v \\
& =\left(2 U s / S V_{0}-C_{0} / S V_{0}\right) d U s / d v=-\left(S U s^{2} / C_{0} V_{0}\right)\left(2 U s-C_{0}\right) / S V_{0} \\
& =-U s^{2}\left(2 U s-C_{0}\right) / C_{0} V_{0}^{2}
\end{aligned}
$$

From equation (16c), we can convert Equation (16e) in terms of $V$ and $V_{0}$ into the following

$$
\begin{aligned}
P_{H} & =\left(U s-C_{0}\right) U s / S V_{0}=\left(S-S V / V_{0}\right) U s^{2} / S V_{0} \\
& =\left(1-V / V_{0}\right) U s^{2} / V_{0}=\left(1 / V_{0}-V / V_{0}^{2}\right) U s^{2} \\
& =\left(1 / V_{0}-V / V_{0}^{2}\right) x C_{0}^{2} /\left(1-S+S V / V_{0}\right)^{2} \\
& =\left(V_{0}-V\right) C_{0}^{2} /\left(V_{0}-S V_{0}+S V\right)^{2}
\end{aligned}
$$

Now as Gruneisen equation of state is stated as $P_{T S}=\gamma / V x E_{T S}$ where pressure is proportional to specific volume and energy $\left(\gamma=V(d P / d E)_{v}=V \alpha j / C_{p}\right.$, since $H=E+P V$, and if we differentiate this equation, we have

$(d E / d V) p=(d H / d V) p-d(P V) / d V$,

$(d E / d V) p=(d H / d T)(d T / d V)-d(P V) / d V$ 
$(d E / d V) p=(d H / d T)(d T / d V)-d(P V) / D v$

$(d E / d V) p=(d H / d T) /(d V / d T)-d(P V) / d V$

Then $H=Q$ (Enthalpy)as $C p=d Q / d T$ and $d V / d T=\alpha . V$ and $(d E / d V) p=(C p / V \alpha) p-P$ and from equation $\gamma=V(d P / d E)_{v}=V \alpha j / C_{p}$, we will have $(d E / d V) p=(j / \gamma) p-P$ which give us $(d P / d E)_{v}$ $=V / \gamma$ and finally,

$d E=[d E / d P] d P+[d E / d V] d V=[(j / \gamma) p-P] d V+[V / \gamma] d P_{H}$

Next, by differentiating Equation (16c),

$d E=-1 / 2\left(P_{H}\right) d V+1 / 2\left(V_{0}-V\right) d P_{H}$

Since, $P^{\prime}{ }_{H}=d P_{H} / d v$ and $P_{H}=P$, Equations (17a and 17b) equals

$d E=[(j / \gamma)-P] d V+[V / \gamma] d P_{H}=-1 / 2\left(P_{H}\right) d V+1 / 2\left(V_{0}-V\right) d P_{H}$

$-1 / 2\left(V_{0}-V\right) d P_{H}+[V / \gamma] d P_{H}=-[(j / \gamma)-P] d V-1 / 2\left(P_{H}\right) d V$

$\left[(V / \gamma)-1 / 2\left(V_{0}-V\right)\right] d P H=-\left[[(j / \gamma)-P]+1 / 2\left(P_{H}\right)\right] d V$

$\left[(V / \gamma)-1 / 2\left(V_{0}-V\right)\right] P^{\prime} H+1 / 2 P_{H}=-(j / \gamma)-P$

As $P=P_{H}$ and $P^{\prime}{ }_{H}=d P_{H} / d V$ substituting on Equation (17b) gives

$(j / \gamma)=-\left[(V / \gamma)-1 / 2\left(V_{0}-V\right)\right] P_{H^{-}}^{\prime} 1 / 2 P_{H}+P_{H}$

$j=-V P^{\prime}{ }_{H}+1 / 2 \gamma\left[\left(V_{0}-V\right) P^{\prime} H+P_{H}\right]$

Further, where $J$ is the bulk modulus and at initial condition when $V=V_{0}$, then

$J=-V P^{\prime}{ }_{H}+1 / 2 \gamma\left[\left(V_{0}-V\right) P^{\prime} H+P_{H}\right]$

$J_{0}=-V_{0} P^{\prime}{ }_{H(V O)}$

And next, where $C_{0} / U s=1-S+S V / V_{0}$, putting $V=V_{0}$ and $C_{0}=U s$ we get

$J_{0}=-V_{0} P_{H(V 0)}^{\prime}=A^{2} / V_{0}$

Now, we know that from Slater formula, we can get $(d K / d p)_{T}=2 \gamma+1 / 3$ and from equation of compressibility, compressibility $K$ is equal to $K=K_{0}+K^{\prime}{ }_{0} p_{i}$ and $K_{0}^{\prime}=(d k / d p)_{T}$ and from thermodynamics principles, then

$J=(1+\alpha \gamma T) K$

$J=(1+\alpha \gamma T)\left(K_{0}+K^{\prime}{ }_{0} p_{i}\right)$

$J=(1+\alpha \gamma T) K_{0}+K^{\prime}{ }_{0} p_{i}(1+\alpha \gamma T)$ 
Next, tet us assume that $p=p_{i}(1+\alpha \gamma T)$ so that

$J_{0}=(1+\alpha \gamma T) K_{0}$

Then by putting $J_{0}, K^{\prime}{ }_{0}$ and $p$ values, we get

$J=J_{0}+(2 \gamma+1 / 3) p$

Substituting Equations (17e) with (17d) can be equated with Equation (17c) as follows

$J_{0}+(2 \gamma+1 / 3) p=-V P^{\prime}{ }_{H}+1 / 2 \gamma\left[\left(V_{0}-V\right) P^{\prime}{ }_{H}+P_{H}\right]$

$J_{0}=-V_{0} P^{\prime}{ }_{H(V 0)}=A^{2} / V_{0}$

$A^{2} / V_{0+}(2 \gamma+1 / 3) p=-V P^{\prime}{ }_{H}+1 / 2 \gamma\left[\left(V_{0}-V\right) P^{\prime}{ }_{H}+P_{H}\right]$

And in terms of $U s$ and $S, A_{s} U s=U_{s}^{t}$ and $S=S^{w}$ demonstrating that

$\gamma=\left[U_{s}^{t}\left(2 U_{s}^{t}-C_{0}\right)\left[C_{0}+\left(S^{w}-1\right) U_{s}^{t}\right]\right.$

$$
\left.-\left(1 / 3 C_{0} U_{s}^{t}\right)\left(U_{s}^{t}-C_{0}\right)-S^{w} C_{0}^{3}\right] / U_{s}^{t}\left(U_{s}^{t}-C_{0}\right)\left(U_{s}^{t}+C_{0}\right)
$$

where $E$ is internal energy, $H$ is enthalpy and $P V$ is the work done due to pressure where $p$ is pressure, $V$ is specific volume, $C_{0}$ and $\mathrm{S}$ are the Hugoniot parameters in the linear relationship between the shock wave velocity $U_{s}^{t}$ and $U_{p}^{t}$ the particle velocity $\left.U_{s}^{t}=C_{0}+S U^{t}\right)$. In general, $C_{O}$ is the bulk velocity of sound, $S$ is linear Hugoniot slope coefficient and $\gamma$ is the Grüneisen. We can then have plot of the value of stress/density of composite at different impactor velocity which give the slope for determining the Gruneisen parameter from Hugoniot equation state equation.

\section{Experiments}

\subsection{Materials}

The resin studied was a commercially available polyester resin system supplied by Mechemco (India) with the trade name Repol. This resin was specially developed to fulfil the requirements of the high impact material in advanced pultrusion processes. The advanced product is reinforced with polymeric waste in hybridisation of glass robbing. The resin is heat curable purposely designed for pultrusion manufacturing method. The resin was fully cured at $130^{\circ} \mathrm{C}$ for 30 mins at atmospheric pressure. The resulting product of composites measuring $500 \mathrm{~mm}$ $\times 500 \mathrm{~mm}$ square and $10 \mathrm{~mm}$ thick lapped to a flatness of $\pm 5 \mu \mathrm{m}$. Density was measured using 
a Micrometrics Accu Pyc 1330 gas pycnometer. The elastic properties of Impactor and densities of composite manufactured and impactor were measured as shown Table II

\subsection{Impact testing}

A common way for measuring the shock Hugoniot of materials is by conducting plate impact experiments which may through accelerated gas gun system, but here we conducted highvelocity powered impact with varying cartridge from white to black as available with Hilti gun. A typical experimental set-up is shown below on Figure 1(a). Here, an impactor piston is accelerated by powder actuation towards the target sample and arrives so that all points on the impactor surface contact the target simultaneously.

\section{Figure 1}

The impact generates a planar shock wave in the target. In this situation, all strain is accommodated along the impact axis while the orthogonal components of strain are zero due to inertial confinement.

The shock response of the resin target was measured using two Vishay Micro measurements Mangan in pressure gauges LS-SS-125CH-048, encapsulated between two layers of $25 \mu \mathrm{m}$ Mylar as shown Figure 2(c). Data acquisition is captured by the software and Module as shown in Figure 2(a) and 2(b). Only steel nails were used as impactor, that is, were accelerated to velocities between $176 \mathrm{~m} / \mathrm{s}$ and $992 \mathrm{~m} / \mathrm{s}$ using a $\emptyset 4-\mathrm{mm}$ diameter and $12 \mathrm{~mm}$ to $30 \mathrm{~mm}$ length reciprocate conical shape with known Hugoniot given in Table II and a typical target set-up is given schematically on Figure 1(b) and three samples were tested for each experiment.

The impactor piston was held by electro-magnetic holder and released on demagnetisation by to trigger powder actuator on target Sample before impact as shown Figure 2(d). The impact energy is varied by regulator attached in gas actuated nail gun. One strain gauge (the 'frontsurface gauge') is fixed at the interface between the cover plate and the test specimen, and the other (the 'back surface gauge') is fixed between the test specimen and the backing material. The shock Hugoniot was measured using the standard impedance matching technique [33]. Before releasing impactor, the thickness of each test specimen was measured, so that the 
distance between the gauges was accurately known. The (assumed constant) shock velocity $(U s)$ was calculated by the transit time $(\Delta \mathrm{t})$ of the shock which was measured by measuring the time of arrival of the shock at each gauge across the specimen. By knowing the Hugoniot of the flyer plate material and the impact velocity, we established a value for the particle velocity $(U p)$ behind the shock. Hugoniot data for our flyer-plate materials were taken from Marsh [34] and the velocities of the impactor were calculated from impact energy as specified in different cartridge used and measured, mass and cross section of impactor as shown in Table III.

Table III.

Capturing arrival and shape of the shock; subsequent data reduction and analysis was done through Fast digital analogue from National Instruments National instruments cDAQ 9171 and NI-9230 Module.

On impact by impactor a shockwave is generated that propagate through the sample. We anticipated that across the shock wave there is an extremely rapid rise in pressure, temperature and density of the medium as expected. The Vishay Micro measurements Mangan in Pressure gauges LS-SS-125CH-048 which were located closely to the back surface of the polyester composite sample, are sensitive to the longitudinal pressure [35]. The pyrometer translates the light signals to electrical signals which are recorded as shown on Figure 3 (a-d).

The jump signals of the pins were clear and therefore accurate travel time $\Delta t$ measurement between the time given by taking an from gauge 1 and gauge 2 . As the thickness $d$ of the second part was measured beforehand as shown in Table IV, the shock wave velocity at target $U^{t} s$ was obtained as $U^{t} s=d / \Delta t[4]$.

Table IV

\section{Results and Discussion}

As shown in Table I, the shock velocity $U_{s}^{t}$ and longitudinal stress $\sigma^{t}$, of composite sample are measured and $\left(U^{t} p, P_{H}, V\right)$ are calculated from our experimental data and shown in Table V. Shear stress, $\tau$ contributes more on increasing velocity beyond certain pressure and it deviates from linearity. Hence Gruneisen parameter of shock thermodynamics is required to get linear graph for higher shock velocity. From Figure 2(e-f) ringing shock travel at front and delamination at back surface are clearly visible. 
Figure 2

In this example, $\varnothing 4-\mathrm{mm}$ diameter and $12 \mathrm{~mm}$ to $20 \mathrm{~mm}$ length reciprocate conical shape steel flyer was accelerated to $270 \mathrm{~m} / \mathrm{s}$ and $588 \mathrm{~m} / \mathrm{s}$ using powder actuated nail gun. It should be noted that the trace of shock wave was measured by sensors bonded at front and back surface of target impacted at a velocity of $588 \mathrm{~m} / \mathrm{s}$ by steel nail as an impactor. During operation of power actuation of the shot, stress history rises rapidly to its maximum value. Two different mood of impact, one, when both gauges are bonded to either of the surface and $2^{\text {nd }}$, impact is conducted when gauge is bonded to back surface only. A typical gauge trace for PE/GFRC is shown below in Figure 3(a-d).

Figure 3

In case one, surprisingly, back-surface and front-surface gauge Figure 3(a-b) shows similar shock stress level with different shock release velocity during impact. The Hugoniot stress is measured, in this example, over the period from 0.8 to $2.92 \mu$ s for front gauge surface and 2.09 to $4.46 \mu$ s for back-surface gauge. Over the period Hugoniot stress level both front and Backgauge surface readings are similar. It is noted that there is an overshoot recorded in Figure 3a, by the front-surface gauge as the measured stress reaches its maximum value for single impact. However, such features are not observed in Figure 3b, for back-surface gauge. Shock stress reflects pressure due to sudden compression of matrix phase which gets compressed to certain extend depending on thickness, configuration and velocity of impact. Hence thicker the plate, less resistant to compression and just opposite in case of thin plate. This apparent rise in stress peak is expected to be broader in case for thicker plate, due to higher degree of compression. This is due to the fast-rising nature of the shock causing ringing [35]. The stress arriving at the gauge is the results of stress developed to compress reinforcing fibres and the binder resins.

As thickness increases from $8 \mathrm{~mm}$ to $10 \mathrm{~mm}$, low gradient of shock stress peak rise observed in Figure 3(c-d), wherein stiff gradient for lower thickness. It is also observed that, stress travels for certain periods and then gets released to surroundings or adjacent plates. The release of shock and its velocity depends on inside materials and surroundings. For single impact, release time of shock of front surface gauge is almost 2.48 micro secs here in for back surface gauge, time to release is 1.32 micro secs. The Hugoniot stress from front lasts for longer to get released 
compare to back Gauge shock. Similarly, for separate impact, at back- surface gauge, for higher thickness, 1.31 micro secs and there is no clear timing observed for higher thickness.

The shock release depends on close match between the shock impedance of the composite sample and the gauge backing substrate. The Hugoniot of many polymers, metals and ceramics can be fitted assuming a linear shock velocity - particle velocity relationship given by the following equation: $U s=C_{0}+S . U_{p}(1)$ where $S$ is the slope and $C_{0}$ is the intercept of the shock velocity axis. This has previously been observed by other researcher for other polymers such as PMMA [36], polyester [37], poly (ether ether ketone) [38] and epoxy resin [39]. For metals, $C_{0}$ has been correlated with the bulk sound velocity of the material whereas $S$ has been theoretically shown to relate to the first derivative of bulk modulus with pressure [40]. The relationship between $p$ and $u$, as shown in Figure 4, is parabola fitted with the least square method: $p=57.119 U^{t} p^{2}+7.6845 U^{t} p$.

Figure 4

As shown in Figure 4(a), the relationship between $U_{S}^{t}$ and $U^{t} p$, which is the Hugoniot curve, is linear fitted with the least square method: $U_{S}^{t}=C_{0}+S_{t} U^{t} p$ So the parameters $\mathrm{C}_{0}$ and $\mathrm{S}_{\mathrm{t}}$ for composite are determined as $C_{0}=(2.872) \mathrm{km} / \mathrm{s}$ and $S_{t}=1.25 \pm 0.063$. With the flyer velocity $U d$ and known Hugoniot of impactor the particle velocity $U^{t} p$ is calculated, and shock wave pressure of the target can be calculated by measured shock wave velocity $U^{t} S$ and density of composite in shock wave equations. The relationship of shock pressure and particle velocity is shown in Figure 4 (b).

There are two points to note here in Figure 4a, firstly a linear line of regression has been fitted through all ten data points resulting in $C_{0}$ and $S$ values of $2.875 \mathrm{~mm} / \mu \mathrm{s}$ and 1.22 respectivel and Secondly experimentally nonlinearity observed in contrast to linearity of determined values However, literature $[41,42]$ have shown that from theoretical considerations Hugoniot for many polymers over a much larger particle velocity range is parabolic instead of linear. Our measured Hugoniot in shock velocity - particle velocity space is in Table V.

Table V

In this study gauges measure the longitudinal stress $(\sigma)$ that consists of a hydrostatic component and a deviatoric component of stress in accordance with $\sigma=P_{H}+4 / 3 \tau$ where $P$ is the hydrodynamic pressure and $\tau$ is the shear stress. Also fitted to the data is a calculation of the 
hydrodynamic pressure calculated by $P_{H}=U_{S}^{t} \rho_{t} U^{t} p$, where $U_{s}$ and $\rho_{t}$ are measured from experiments and $U_{P}^{t}$ are calculated from shock parameters used in Hugoniot equation. Note that there is a good fit for the data at the lower particle velocities indicating that the material is behaving hydrodynamically. However, it is clearly seen in Figure 4(b) that beyond certain shock stress, measured longitudinal stress exceeded predicted value by the hydrodynamic curve. A possible hypothesis to explain this is that steric hindrance to compression increases, as initially separate polymer chains are brought closer together and begin to interact. This hindrance in compression depends on thickness of target, the fabric configuration in composite making and laminates used as well as the increase in steric hindrance due to pendent groups in polymer back chain may have increased the resistance to compression. The shock parameters have been summarised for composite plate from several sources $[43,44,45]$ for glass fibrereinforced bidirectional and unidirectional composites. In the present study the polyester/ GFRC is a pultruded product of polyester resin and waste polymer fibres and this product contains $60 \% \mathrm{v} / \mathrm{v}$ of waste polymers and $5 \%$ of bidirectional glass fibres which when pulled in machine directions shows less alignment in transverse direction that results in different sound velocity in 0/90 degree. Apart from resin type, increase in volume\% of physically bonded polymer reinforcement drastically increases damping properties of composites as compared to glass fibre content

In this work, as polyester resin is crosslinked with styrene as crosslinking monomers, it is concluded that increasing the size of the side groups, with polystyrene (having a phenyl side group) showing a departure from the hydrodynamic curve. For polyester/ GFRC, this occurs beyond $4.02 \mathrm{GPa}$ at $3.5 \mathrm{~mm} / \mu \mathrm{s}$ particle velocity. Other published work [45] on a range of polymers has shown that the stress level at which departure from the hydrodynamic curve occurs can be modified by the choice of the side group attached to the main polymer chain. Similar behaviour has been observed in a range of materials from polymers, $[43,45]$ epoxy resins [42] and ceramics [43, 46] and it is evidence that this resin-based composites material possesses an ability to strengthen with increasing shock stress. We believe that our results are consistent with this viewpoint and the for polyester/GFRC this shown to occur at $3.5 \mathrm{~mm} / \mu \mathrm{s}$. The shock parameters from our experiments are shown in Table V, where in Figure $4 \mathrm{~b}$, nonlinearity in longitudinal shock stress with composite Samples is not prominently observed, due to low impact velocity but Grunisen parameter in Figure 5a, shows linearity with very negligible gradient change. Since the velocity of impact is not high, shock stress received is not showing exponential and maintaining linearity. 
Figure 5

Nevertheless, for higher impact velocity, it is reported [45] that shock stress shows parabolic graph with particle. To avoid interpretation through least square method, liner scale Grunesin parameter fitting is preferred [50]. In Figure 5(b), linearity behaviour is observed in Grunisen parameter when plotted against $(1-U s / U p)=V / V_{0}$. The intercept will value initial condition assuming $V=V_{0}$ which considered the initial state of Grunesin parameter. It is noted that the initial Grunesien from intercept is 0.4517 which is pressure during initial condition. Again, negative linear gradient is observed from regression of impact velocity and specific volume change. Hence as we increase impact velocity, change in specific volume is expected to rise.

\section{Conclusions}

In this study, experimental study was conducted to measure the shock and release behaviour of PFR/GFHC that is used in the commercial manufacture of technological and commodity products prone to shock and high velocity impact. The Hugoniot in shock velocity - particle velocity space is given by $U s=2.1561 U p+2.5734$. The Hugoniot is similar into that of shock velocity-particle velocity space for resins of differing composition as also noted in the literature and as discussed in this work. At higher shock stresses, the behaviour of the resin exhibits an increase in shear stress behind the shock wave in common with many other polymers. The specific reason for this is unclear although for other polymers this behaviour has been suggested as being due to side groups restricting compression between polymer chains. This increasing longitudinal shock pressure as measured with higher velocity is deviating from linear equation as calculated from hydrodynamic shock pressure. Hence linearity graph is suggested for high velocity impact and higher stress. As we conducted impacts ranges from $200-850 \mathrm{~m} / \mathrm{s}$, changes in Grunisen parameter with specific volume is hardly noticeable. In our study inverse linearity is observed on specific volume with impact velocity conditions.

\section{References}

1. Russell SJ. Handbook of nonwovens. The Textile Institute: Woodhead Publishing;2007 
2. Cunniff PM.Ananalysis of the system effects in woven fabrics under ballistic impact.TextResJ1992;62(9):495-509.

3. GuB.Analytical modelling for the ballistic perforation of planar plain- woven fabric target by projectile. Compos PartB2003;34(4):361-71.

4. Sockalingam S, Chowdhury S C, Gillespie JW, Keefe M. Recent advances in modelling and experiments of Kevlar ballistic fibrils, fibers,yarns and flexible woven textile fabricsareview.TextResJ2016.

5. Tabiei A, Nilakantan G. Ballistic impact of dry woven fabric composites are view. Appl Mech Rev2008;61(1):010801.

6. Cheeseman BA, Bogetti TA. Ballistic impact into fabric and compliant composite laminates. ComposStruct2003;61(1_2):161-73.

7. Parsons EM, King MJ, Socrate S. Modeling yarn slip in woven fabric at the continuum level: simulations of ballistic impact. JMech Phys Solids 2013;61(1):

8. Utomo BH, Ernst L, Detailed modelling of projectile impact on dyneema composite using dynamic properties. J Solid Mech Mater Eng 2008;2(6):707-17

9. Jubera R, Ridruejo A, Gonzalez C, L Lorca J. Mechanical behaviour and deformation micromechanisms of polypropylene nonwoven fabrics as a function of temperature and strain rate. Mech Mater 2014;74:14-25

10. Ridruejo A, Gonz_alez C, L Lorca J. Damage micro-mechanisms and notch sensitivity of glass-fiber nonwoven felts: an experimental and numerical study.J Mech PhysSolids 2010;58(10):1628-45.

11. Chocron S, Pintor A, Cendon D, Galvez F,Sanchez Galvez V. Simulation of ball is-tic impact in a polyethylene non-woven felt. $20^{\text {th }}$ International symposiumon ballistics. Orlando;2002.p.23-7.

12. Martínez-Hergueta F, Ridruejo A, Galvez F, Gonz_alez C, LLorca J.Influence of fiber orientation on the ballistic performance of needle punched nonwoven fabrics.MechMater2016;94:106-16.

13. Thomas HL, Bhatnagar A, Wagner LL. Needle-punched non-woven for high fragment protection. $14^{\text {th }}$ International conference of composite materials, San Diego, California;2003.

14. Ipson T W, Wittrock E P. Response of non-woven synthetic fiber textiles to ballistic impact.Tech.rep.no.tr-8m.Denver Research Institute;1966. 
15. Kędzierski P, Gieleta R, Morka A, Niezgoda T, Surma Z. Experimental study of hybrid soft ballistic structures. Composite structures; 2016.

16. Naik D, Sankaran S, Mobasher B, Rajan S, Pereira J. Development of reliable modelling methodologies for fan blade out contain mentanalysis Part I: Experimental studies. Int J Impact Eng 2009; 36(1):1-11.

17. Stahlecker Z, Mobasher B, Rajan S, Pereira J. Development of reliable modelling methodologies for engine fan blade out containment analysis.partII:finite element analysis. IntJ Impact Eng 2009;36(3):447-59.

18. Lee SH, Kang TJ. Mechanical and impact properties of needed punched nonwoven composites.J Compos Mater2000;34(10):816-40.

19. Russel 1S, Pourmohammadi A, EzraI, Jacobs M. Formation and properties of fluid jet entangled HMPE impact resistant fabrics. Compos SciTechnol2005;65(6):899-907.

20. Lin CC, Huang CC, Chen YL, Lou CW, Lin CM, Hsu CH, et al. Ballistic-resistant stainless steel mesh compound nonwoven fabric. FibersPolym2009;9(6):761-7.

21. Lin CC, Lin CM, Huang CC, Lou CW, Meng HH, Hsu CH, etal. Elucidating the design and impact properties of composite non-woven fabrics with various fila-ments in bullet proof vest cushion layer. TextResJ2009;79(3):268-74.

22. Kocer HB.Laminated and hybrid soft armor systems for ballistic applications. Auburn University;2007Master'sthesis.

23. D. E. Munson and R. P. May., J. Appl. Phys., 43, 962 (1972).

24. N. Barnes, N.K. Bourne and J.C.F. Millett, In Shock Compression of Condensed Matter2001, edited by M.D.Furnish, N. N. Thadhani and Y. Horie, (AIP) p 135.

25. N. K. Bourne, J. C. F. Millett, N. Barnes, I Belcher, In Shock Compression of Condensed Matter-2001, edited by M.D.Furnish, N. N. Thadhani and Y. Horie, (AIP) p 649.

26. J. C. F. Millett, N. K. Bourne and N. R. Barnes, J. Appl. Phys., 926590 (2002).

27. Tsai L, Prakesh V, Rajendran AM, Dandekar DP, Structure of shock waves in glass fiber reinforced polymer matrix composites. Appl Phys Lett 2007; 90: 061909.

28. Dandekar DP, Hall CA, Chhabildas LC, Reinhart WD. Shock response of a glass-fiberreinforced polymer composite. Compos Struc 2003;61: 51-59.

29. Ruoff L. Linear Shock-Velocity-Particle-Velocity Relationship, J of Appl Phys 1967;38:4976 -. 
30. Hazell PJ, Stennett C, Cooper G. The shock and release behavior of an aerospace-grade cured aromatic amine epoxy resin. Polymer Compos 2008; 29 (10): 1106-1110. DOI $10.1002 /$ pc. 20614 .

31. Millett JCF, Bourne NK, Meziere YJE, Vignjevic R, Lukyanov A, The effect of orientation on the shock response of a carbon fibre-epoxy composite, Compos Sci and Tech 2007;67:3253-3260

32. Millett JCF, Meziere YJE, Bourne NK. The response to shock loading of a glass-fibreepoxy composite: Effects of fibre orientation to the loading axis. J Phys D: Appl Phys 2007; 40 (17): 5358-5365

33. Davison L and Graham RA. Shock compression of solids. Phys Reports (Review Section of Physics Letters) 1979;55:255-379.

34. Marsh SP. LASL Shock Hugoniot Data. University of California Press, Los Angeles, (1980).

35. Millett JCF, Meziere YJE, Bourne NK. The response to shock loading of a glass-fibreepoxy composite: Effects of fibre orientation to the loading axis. J Phys D: Appl Phys 2007; 40 (17): 5358-5365

36. Millett JCF, Bourne NK, Meziere YJE, Vignjevic R, Lukyanov A, The effect of orientation on the shock response of a carbon fibre-epoxy Composite, Compos Sci and Tech 2007;67:3253-3260

37. A C Pereiraa, F S de Assisa, F da C G Filhoa, M S Oliveiraa, E S Limaa, H A C Loperab, S N Monteiroa 'Evaluation of the Projectile's loss of Energy in Polyester Composite Reinforced with Fique Fiber and Fabric’Materials Research. 2019; 22(suppl. 1)

38. P J Hazell, C Stennett, G Cooper, The effect of specimen thickness on the shock propagation along the in-fibre direction of an aerospace-grade CFRP laminateComposites: Part A 40 (2009) 204-209

39. Hazell PJ, Stennett C, Cooper G. The shock and release behavior of an aerospace-grade cured aromatic amine epoxy resin. Polymer Compos 2008; 29 (10): 1106-1110. DOI 10.1002/pc.20614.

40. Ruoff L. Linear Shock-Velocity-Particle-Velocity Relationship, J of Appl Phys 1967;38:4976 -.

41. D. P. Dandekar and D. E. Grady, In Shock Compression of Condensed Matter 2001, edited by M.D. Furnish, N. N. Thadhani and Y. Horie, (AIP), p 783.

42. J.C. F. Millett and N. K. Bourne, J. Phys. D: Appl. Phys. 37, 2901 (2004).

43. H. Chen W. Tang, X. Ran, M. Zhang, Z. Xu. Measurement of the Mie-Grüneisen equation of state for polyimide. Chinese Science Bulletin. 2013 Feb 1;58(6):585-8. 
44. Y. K. Huang, Direct Method of Calculating the Grüneisen Parameter $\gamma$ Based on Shock Wave Measurements of Metals-Journal of Chemicl Physics, volume 51, number 615 september 1969

45. K. Bourne, J. C. F. Millett, N. Barnes, I Belcher, In Shock Compression of Condensed Matter-2001, edited by M.D.Furnish, N. N. Thadhani and Y. Horie, (AIP) p 649.

46. A C Pereira , A M Lima 1, L C Demosthenes ,M S Oliveira, U O Costa, W B A Beze, S N Monteiro, R J S Rodriguez, J F de Deus and W A Pinheiro 'Ballistic Performance of Ramie Fabric Reinforcing Graphene Oxide-Incorporated Epoxy Matrix Composite' Polymers 2020, 12, 2711 


\section{Caption of Tables and Figures}

\section{Tables}

Table I: Details of knowns and un-knowns when calculating the particle velocity of target

Table II: Hugoniot and elastic properties of impactor used in this study

Table III: Physical parameters of impactor (nail) and impact velocity

Table IV: Measured shock wave parameters of composites

Table V: Measured experimental values and determined Hugoniot for composites

\section{Figures}

Figure 1: (a) High impact technique through powder actuated nail gun and (b) Schematic target assembly

Figure 2: (a) Instrument Module image, (b) Wave form Image of the Digital Display.

(c) Image Manganin Pressure Sensor fixed at Sample surface, (d) Before impact image of Sample with cover plate

(e) After impact ringing image due to shock at font, (f) after impact delamination image due to shock at back surface

Figure 3: (a) Trace for appearing shock at from 'Front Gauge' at $5 \mathrm{~mm}$, (b) trace for appearing shock from 'Back Gauge' at $5 \mathrm{~mm}$ plate, (c) trace for appearing shock from 'Back Gauge' at $8 \mathrm{~mm}$ plate, (d) trace for appearing shock from 'Back Gauge' at $10 \mathrm{~mm}$ plate

Figure 4: (a) Measured Hugoniot of plate at shock velocity and particle velocity space, (b)

Measured longitudinal stress and calculated pressure with particle velocity up during shock travel.

Figure 5: (a) Fitting Gruneisen parameter and ration of change in specific volume $v_{0} / v$,

(b) fitting ration of change in specific volume $\mathrm{V}_{0} / \mathrm{V}$ with impact velocity 
Table I

\begin{tabular}{|c|c|c|c|}
\hline \multicolumn{2}{|r|}{ Theoretical } & \multicolumn{2}{|c|}{ Experimental } \\
\hline Known & Unknown & Known & Unknown \\
\hline $\begin{array}{l}S i=\text { For } \\
\text { impactor as } \\
\text { steel known } \\
\text { Hugunoit } \\
C_{0}=\text { Sound } \\
\text { Velocity in the } \\
\text { impactor }\end{array}$ & $\begin{array}{l}U^{t} p=\text { Particle velocity of the } \\
\text { Sample } \\
U^{i} p=\text { Particle velocity of the } \\
\text { Impactor }=\left(U d-U^{t} p\right) \\
P^{t}(\text { Hydrodynamic Pressure) }= \\
U^{t} \rho_{t} U^{t} p \\
U^{t} \rho_{t}=U_{S}^{i} \rho i=Z 1=Z 2= \\
\text { Impedance ---(i) } \\
» U_{S}^{i}=C_{0}+S i U^{i} p \\
» \text { Calculated shock velocity } \\
U^{t}=\left(U_{S}^{i} \rho i\right) / \rho w \\
\sigma^{t} \quad=\quad P^{t} \quad \text { (hydrodynamic } \\
\text { pressure) }+4 / 3 \tau \text { (shear stress) } \\
\tau=3 / 4\left(\sigma^{w}-P^{w}\right)\end{array}$ & $\begin{array}{l}U^{t} s=\text { Shock velocity } \\
\text { travelled (thickness } \\
\text { /transit time shock } \\
\text { wave) } \\
\rho_{t}=\text { Density of the } \\
\text { material composite } \\
\sigma^{t}=\text { Pressure at the } \\
\text { interface } \\
\text { (longitudinal stress) } \\
U d=\text { Velocity of the } \\
\text { impactor at the time } \\
\text { of Impact is } \\
\text { calculated from } \\
\text { Longitudinal } \\
\text { mastress and of the } \\
\text { Impactor (Nail) }\end{array}$ & $\begin{array}{l}U^{i} p=\text { Particle } \\
\text { velocity of the } \\
\text { impactor }\end{array}$ \\
\hline
\end{tabular}


Table II

\begin{tabular}{|c|c|l|c|c|}
\hline Material & $\begin{array}{c}\text { Density of } \\
\text { Impactor } \\
\mathrm{g} / \mathrm{cc}\end{array}$ & $\begin{array}{l}\text { Density of Glass } \\
\text { Hybrid Polyester } \\
\mathrm{g} / \mathrm{cc}\end{array}$ & $\begin{array}{c}\text { Sound Velocity } \\
\text { for } \\
\text { Impactor }\left(\mathrm{C}_{0}\right) \text { in } \\
\mathrm{m} / \mathrm{s}\end{array}$ & $\begin{array}{c}\text { Hugoniot } \\
(\mathrm{Si})\end{array}$ \\
\hline Mild Steel & 7.8 & 1.25 & 3.754 & 1.92 \\
\hline
\end{tabular}


Table III

\begin{tabular}{|c|c|c|c|}
\hline Material & $\begin{array}{c}\text { Energy in } \\
\text { Joules }\end{array}$ & $\begin{array}{l}\text { Weight of Nail Used } \\
\text { (Grams) }\end{array}$ & $\begin{array}{c}\text { Velocity of Impact } \\
\text { considering 65\% } \\
\text { Energy Transfer (m/s) }\end{array}$ \\
\hline & 52 & 0.2 & $401.3,456.1,501.2$ \\
Mild Steel & 62 & 0.4 & $295.5,324.0,361.2$ \\
& 85 & 0.6 & $262.1,243.4,298.3$ \\
\hline
\end{tabular}


Table IV

\begin{tabular}{|l|l|l|l|l|l|l|l|l|l|}
\hline Pressure, (GPa) & 17.36 & 13.98 & 10.63 & 8.33 & 6.73 & 6.40 & 4.09 & 3.43 & 3.10 \\
\hline $\begin{array}{l}\text { Shock Wave } \\
\begin{array}{l}\text { Velocity, Us } \\
\text { (mm/ms) }\end{array}\end{array}$ & 2.69 & 2.60 & 2.51 & 2.31 & 2.18 & 2.12 & 2.15 & 1.99 & 1.92 \\
\hline $\begin{array}{l}\text { Impact Velocities } \\
\mathrm{mm} / \mathrm{ms}\end{array}$ & 0.501 & 0.456 & 0.40 & 0.36 & 0.32 & 0.295 & 0.276 & 0.243 & 0.262 \\
\hline
\end{tabular}


Table V:

\begin{tabular}{|c|c|c|c|c|c|}
\hline $\begin{array}{l}\text { Gruneisen } \\
\text { Parameter }\end{array}$ & $V_{0} / V$ & $\begin{array}{c}\text { Particle Velocity } \\
\text { of Target } \\
\text { Calculated } \\
\mathrm{m} / \mathrm{s}\end{array}$ & $\begin{array}{l}\text { Intercepts } \\
\mathrm{C}_{0} \text { in } \mathrm{m} / \mathrm{s} \\
\text { for Target }\end{array}$ & $\begin{array}{l}\text { Hugoniot } \\
\text { of Target } \\
\qquad\left(S_{t}\right)\end{array}$ & $\begin{array}{l}\text { Pressure } \\
\text { Calculated } \\
\quad(\mathrm{GPa})\end{array}$ \\
\hline 0.4601 & 0.803 & 0.250 & \multirow{9}{*}{2.8734} & \multirow{9}{*}{1.22561} & 5.895854069 \\
\hline 0.4601 & 0.803 & 0.279 & & & 6.799554189 \\
\hline 0.4599 & 0.803 & 0.304 & & & 8.007399951 \\
\hline 0.4599 & 0.803 & 0.312 & & & 8.11629326 \\
\hline 0.4599 & 0.803 & 0.340 & & & 9.056170017 \\
\hline 0.4598 & 0.803 & 0.379 & & & 10.75389909 \\
\hline 0.4596 & 0.803 & 0.424 & & & 13.04281034 \\
\hline 0.4596 & 0.803 & 0.473 & & & 15.07827532 \\
\hline 0.4595 & 0.803 & 0.530 & & & 17.47418739 \\
\hline
\end{tabular}




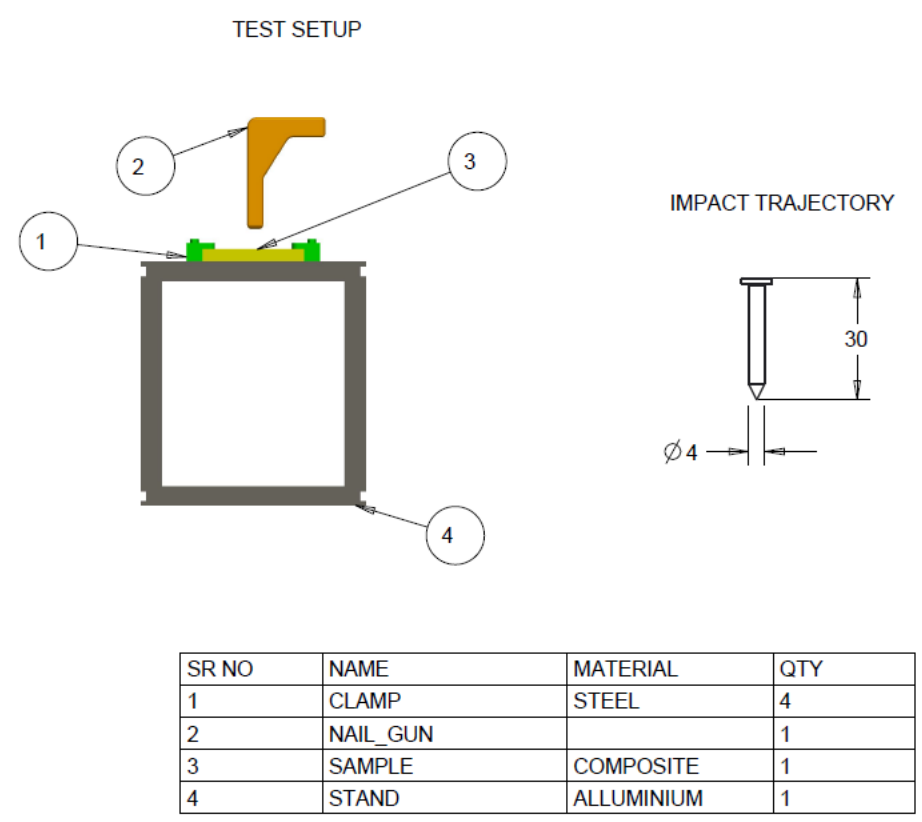

(a)

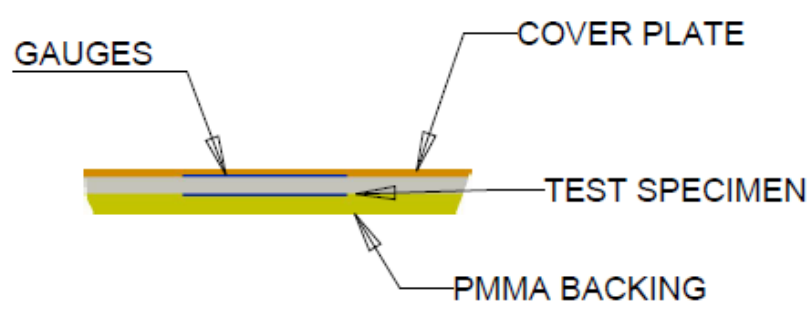

DETAIL A

(b)

Figure 1: (a) High impact technique through powder actuated nail gun and (b) Schematic target assembly 


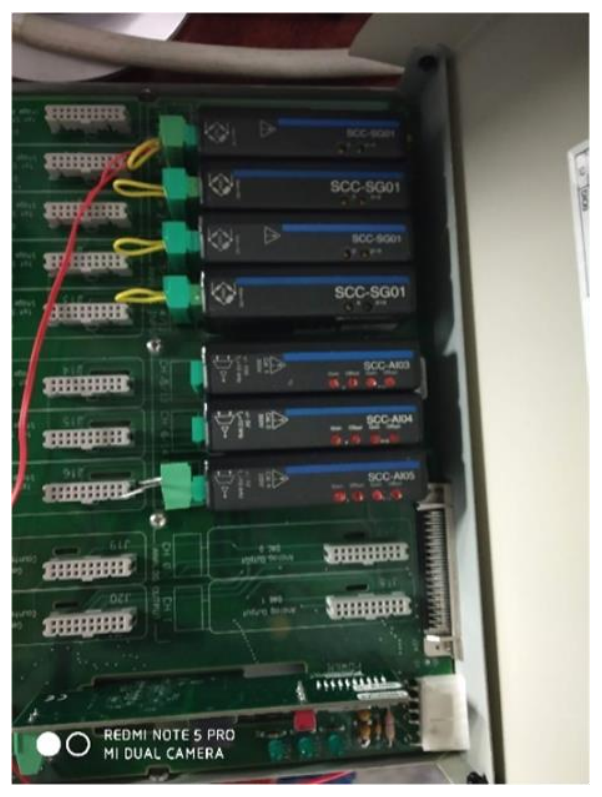

(a)

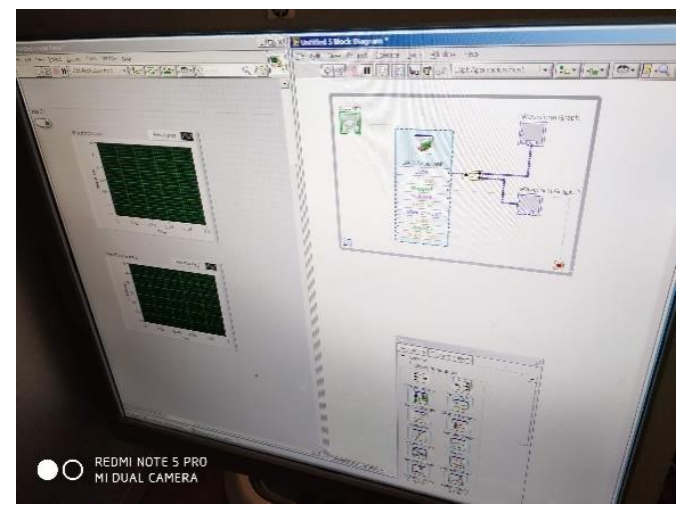

(b)

Figure 2

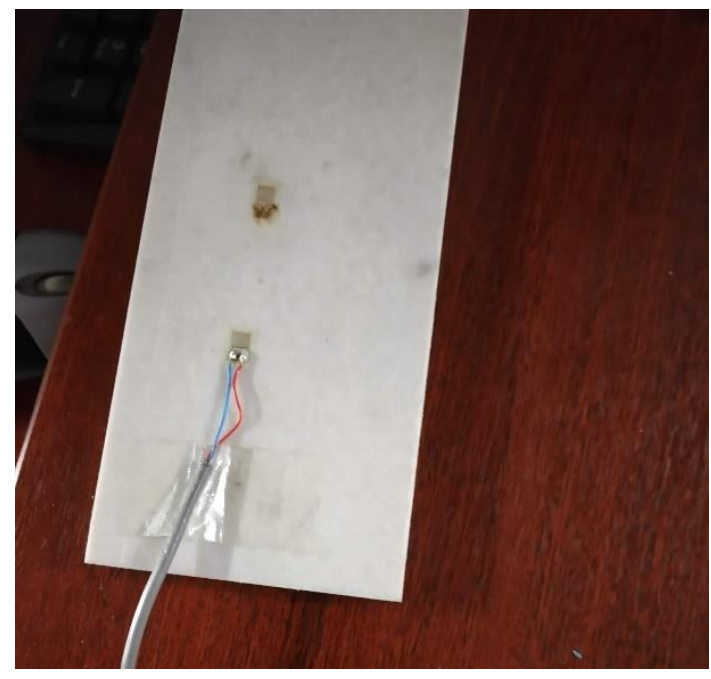

(c)

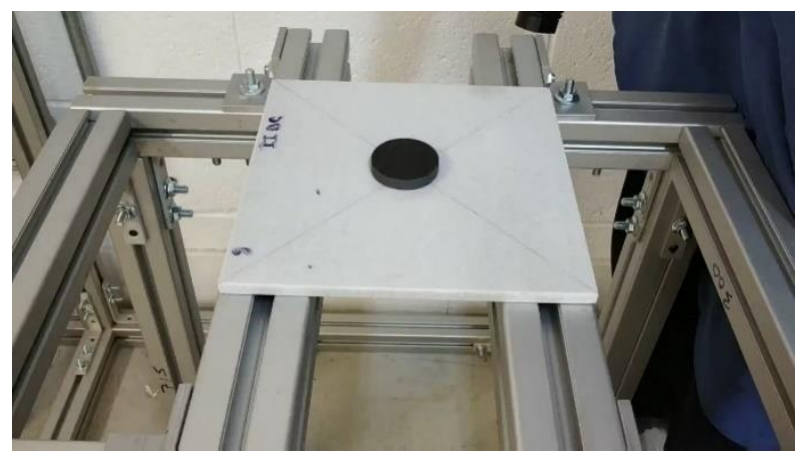

(d)

Figure 2 


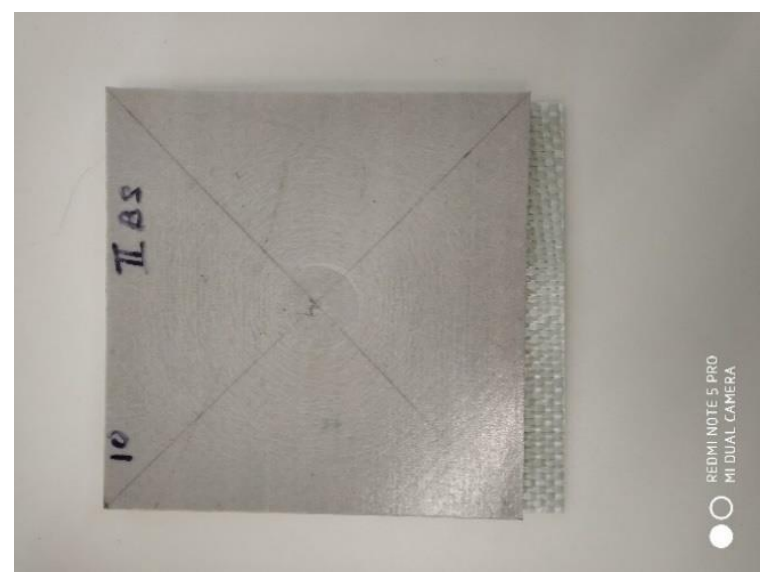

(e)

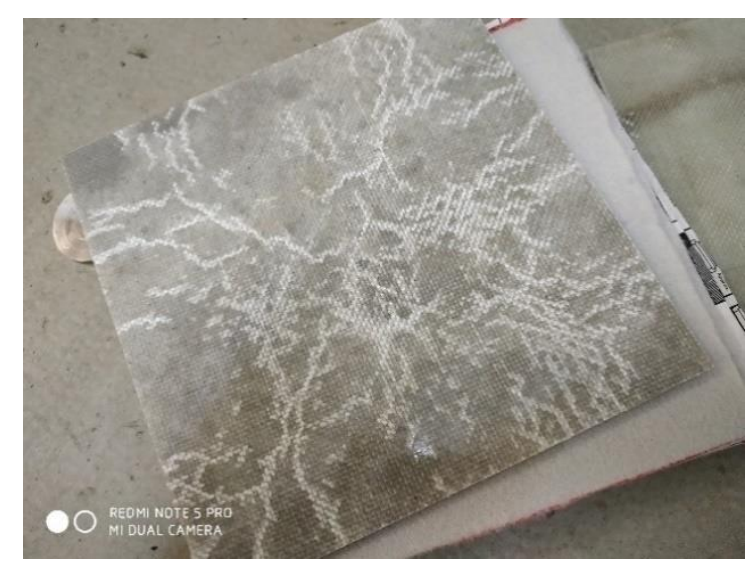

(f)

Figure 2 


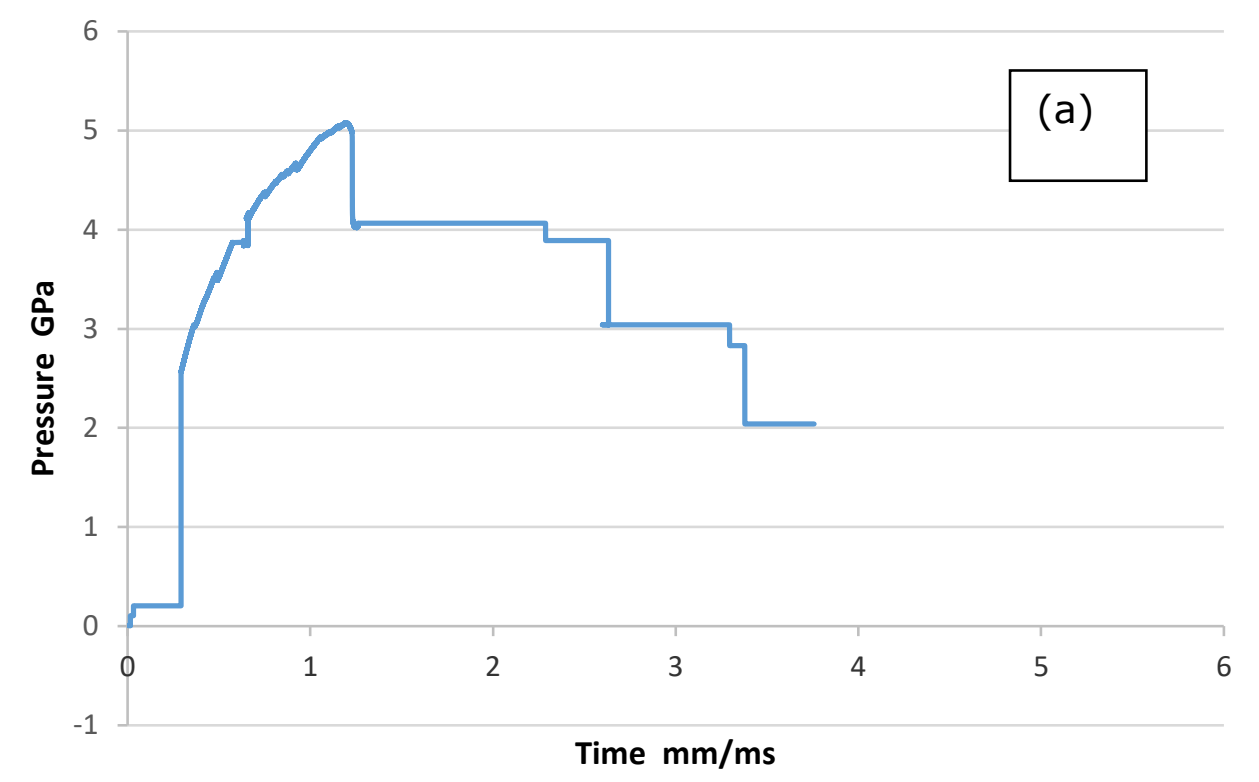

(b)

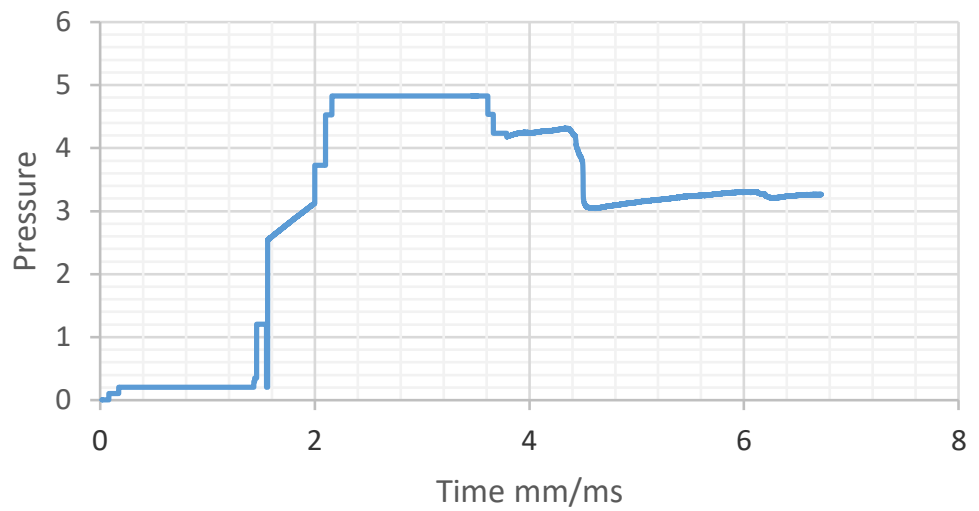



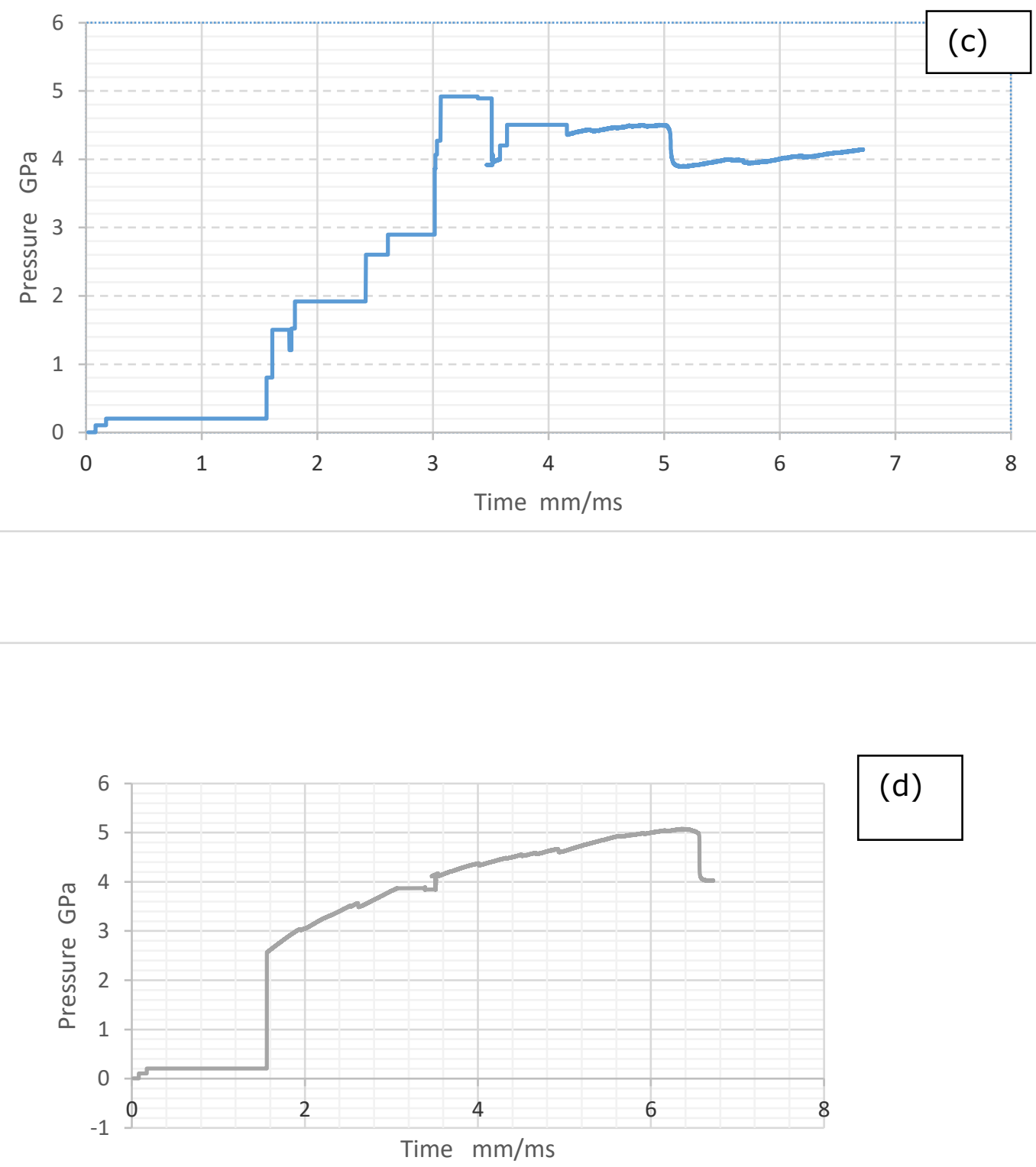

(d)

Figure 3 

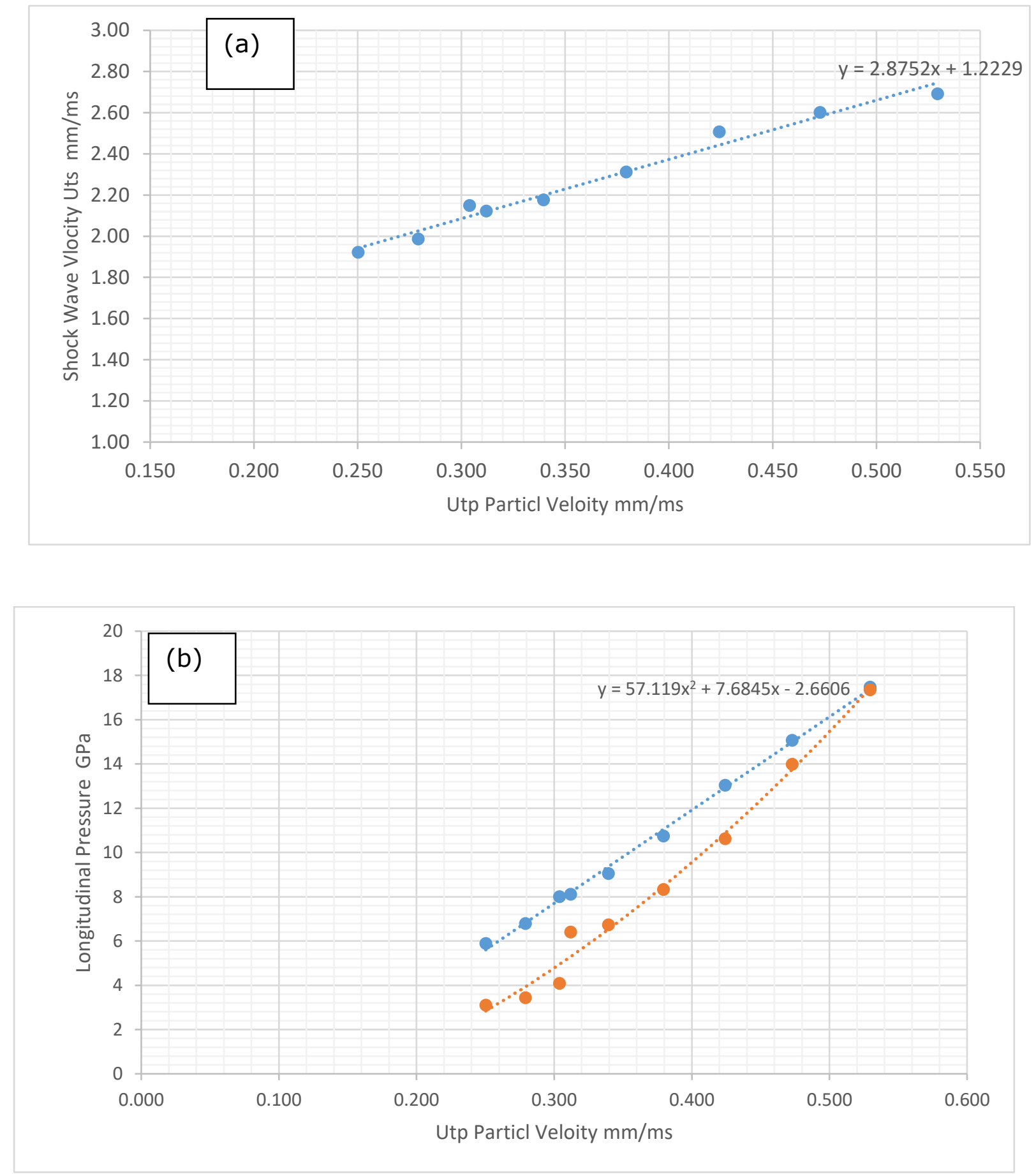

Figure 4 


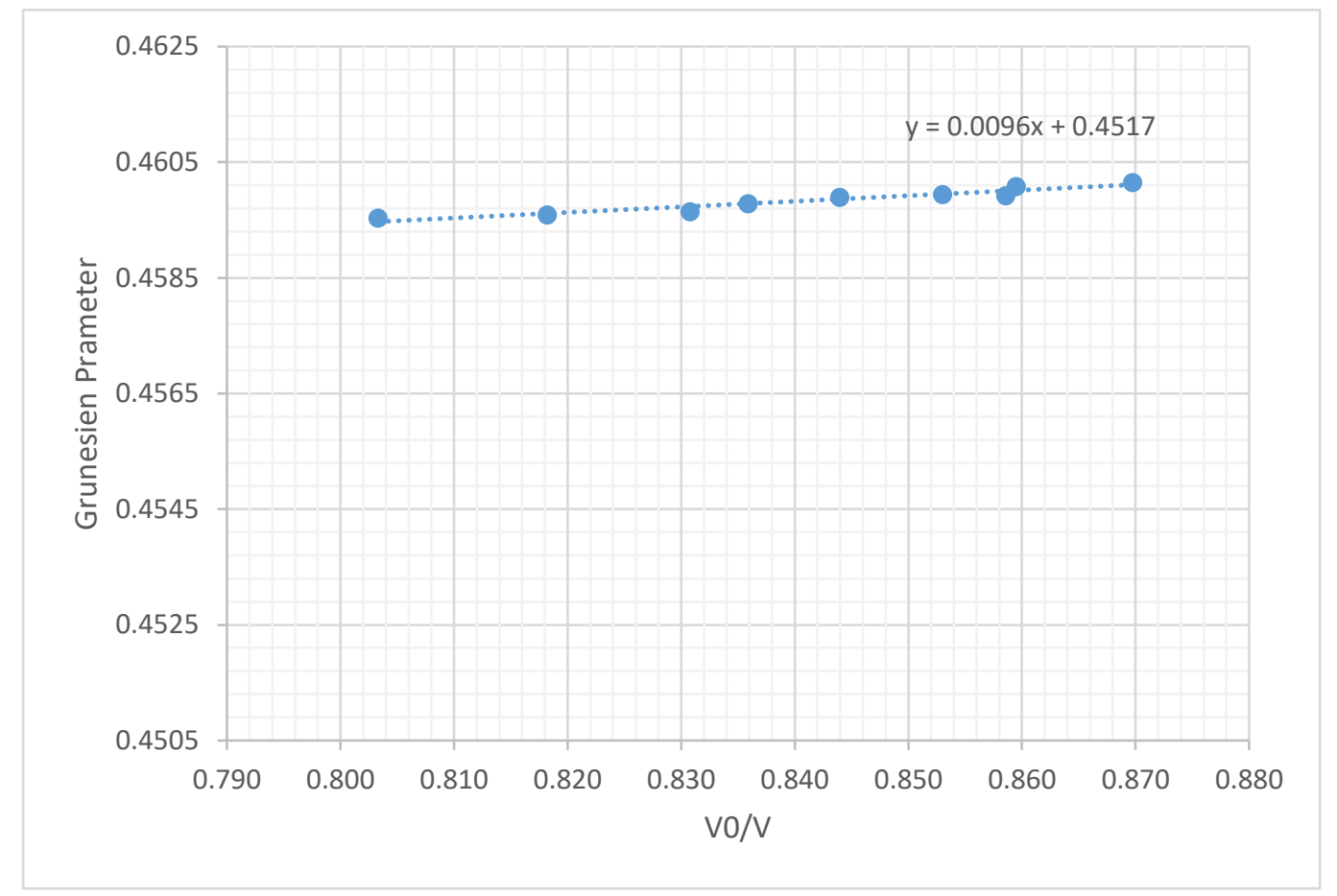

(a)

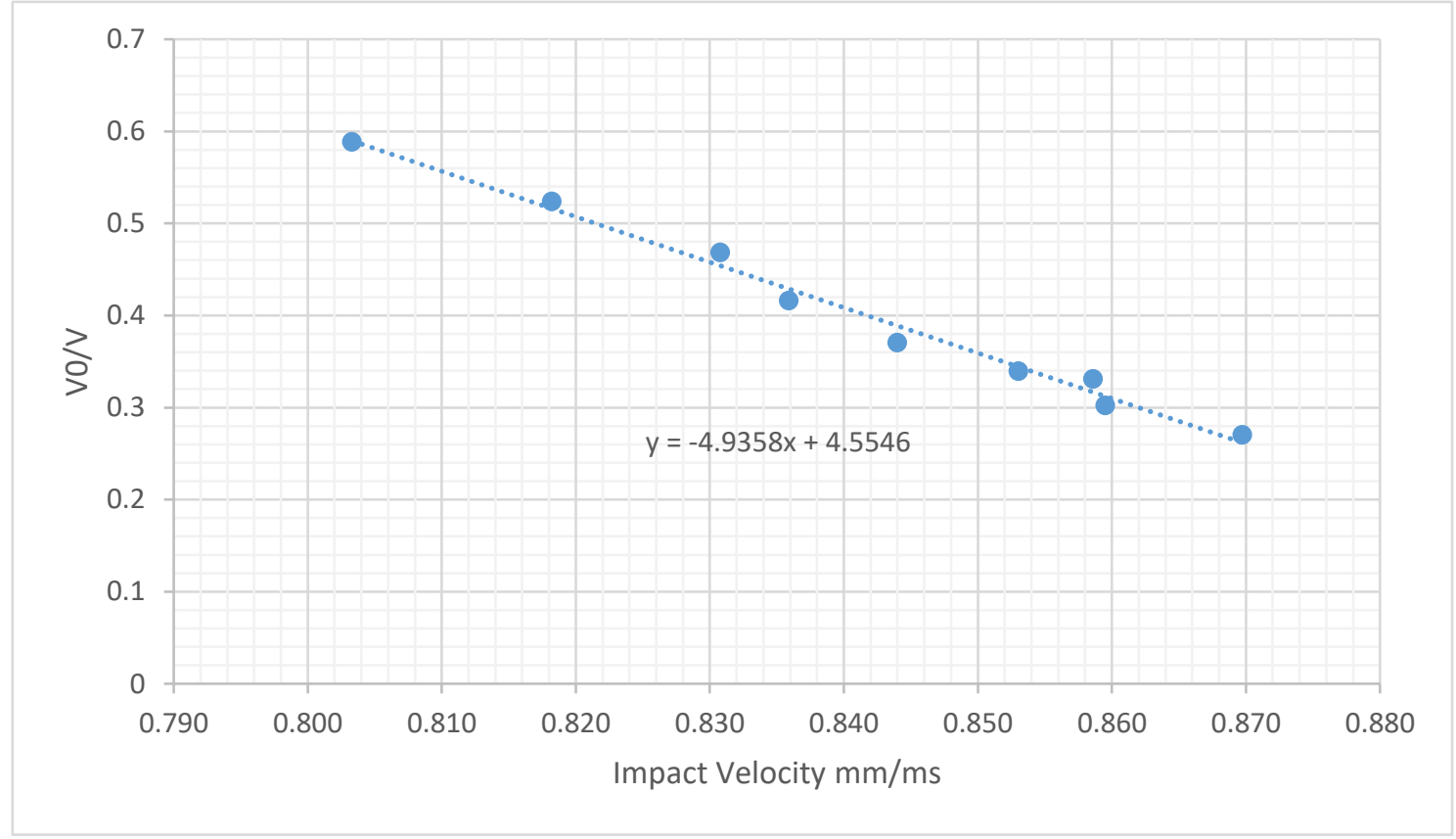

(b)

Figure 5 